\title{
Measuring spatial variations in sports talent development: the approach, methods and measures of Talent Tracker
}

\section{Geoff Woolcock and Matthew Burke}

\begin{abstract}
Knowing where sports talent is produced is fundamental to identifying spatial factors in talent production and to assist with talent identification. This research develops spatial analysis methods - the Talent Tracker - to harness geographical information systems and identify regions that are over- and under-producing sports talent. The approach focuses on the professional Australian Football League (AFL), using data sourced from the AFL itself and other sources, to identify differences in regional 'talent yield' based on junior participation. Data from AFL draft records, informants and secondary sources identified the place of junior talent development for the 1,290 players who were drafted and played at least one game of senior AFL football in the period 1997-2010. AFL National Census data identified junior participation for 94 specified regions for the period 2002-2009. AFL talent was assigned to these regions by using ArcGIS procedures, and the datasets synthesised to produce tables and maps of talent yield by participation for each of the 94 AFL regions. The results demonstrate the power of contemporary spatial analysis to open up new research methods for studies into sports talent production and identification. Clear spatial patterns emerge in talent yield at both the national and metropolitan scales. The results provide numerous avenues for further research to explore determining factors for the spatial patterns identified.
\end{abstract}

\section{Key Words}

talent identification, sports geography, geographic information systems, Australian Football League 


\section{Introduction}

Champion sportspersons might not grow on trees but they do spend their formative years in particular cities, towns and regions. This paper provides methods for exploring spatial differences in sports talent production, their application to the Australian Football League, and the spatial landscape that emerges across Australia and within key metropolitan areas. Previous research has highlighted that amongst the many influences on sports talent development, socio-spatial factors often play a key role. There is much interest in what types of places tend to produce champions within the sports industries. The theoretical and conceptual framework for sports talent development draws on the set of integrating factors believed to be of most influence. Bailey et al. (2010:6) posit a biopsychosocial model of talent development that focuses on 'the biological domain, the psychological domain and the social domain'. Within the social domain there is significant attention being given to socio-spatial factors in sports talent production. This fits with the broader trend in sports geography that for decades now has focused on questions that lie at the intersection between geography and the sociology sport, often by integrating empirical spatial analysis with history, sociology and other disciplines (Maguire 1995:21). Sport has many spatial dimensions, including the distributions of clubs and players, its organisation into competitions, the distribution of community affiliations and attachment, effects on socio-spatial processes, impacts on geopolitics and nationalism, and the geography of economic impacts from professional sports (McGowin 2010). Implicated are a set of economic, institutional and environmental processes that shape sports landscapes and in turn influence player production.

Australian and North American sports geographers have explored differences in the spatial patterning of player recruitment to determine whether there are birthplace effects. Explicit examinations of geographies of talent 'production' (where talent is sourced) include research by Abernethy and Farrow (2005), Côté et al. (2006) and Curtis and Birch (1987). There are limitations in these studies in that the approaches used have tended to ignore the locations where players are actually developed, focusing instead on measures such as their place of birth, which is a weak marker given Australia's traditionally high rates of residential mobility. We provide here a different approach, showing it is possible to gather rich geographical information on sports talent by place of junior development, to geo-code that information, and to synthesise it with data on participation and on broader population variables. This approach is applied to data for players recruited to the professional Australian Football League (AFL), the indigenous game of 'Australian rules' football, from 1997-2010. Players' place of junior development, identified as the club or school where they were registered whilst playing during the ages of 11 to 15 was captured through national AFL Draft records, secondary sources and information provided by key informants. This information was geo-coded, aggregated to the level of AFL regions, matched with junior participation data, and synthesised with Australian Bureau of Statistics data for these population regions. The result is Talent Tracker, a tool that identifies spatial variation in player talent production.

The first contribution advanced in this paper is methodological. We are not aware of any attempt at this scale to track the specific locations where talent has been developed, with this level of precision, cross-matched with population and junior participation data, to allow for the identification of regions where players are disproportionately being produced. The method outlined here demonstrates a coherent and achievable means to locate those places that appear to be doing something 'right' in producing sports talent, and those places that are not. This opens the potential for significant new research in better isolating and exploring the factors most critical to sports talent development and offers a more sophisticated process that may significantly improve talent identification. The second contribution is in providing the sports geography of talent production, at this 
improved level of precision, for the sport of AFL in Australia at both national and metropolitan scales.

The paper is organised as follows: first, the development of socio-spatial sports research is outlined, with advances made in the field and current problems and limitations outlined. The problem of identifying the geography of talent production is explored in depth, which leads to a detailed outline of the core approach and the methods used. Results and mapping are provided at the national scale, and also at the metropolitan scale for Melbourne, Adelaide and Perth. The discussion draws attention to the benefits and costs of the approach and methods, and suggests how this work both opens up new avenues for research across a range of sports and other activities. The discussion also questions what this work may mean for sports talent identification.

\section{Sports geography research, socio-spatial factors and player production}

Much recent research in sports geography has been focused on the location of playing facilities (i.e. Burke and Woolcock 2009), socialisation benefits of sports in communities (Nicholson and Hoye 2008), its possibilities for discrimination, exclusion and social stratification (Collins 2003) and its development of a sense of place and local identification (Harris \& Wise 2011; Bale 2003; Rowe and McGuirk 1999). In Australia, there has been significant interest in such issues in mapping and describing patterns of community interest based on the territorial organisation of AFL football (Rimmer and Johnston 1967), exploring the role sports and sporting clubs play in building social capital (Zakus, Skinner and Edwards 2009; Rosso 2010) and examining how economic restructuring and other processes impact on sporting clubs, competitions and their social functions (Tonts and Atherley 2005). But referring to the broader field of the 'geography of sports' in the Encyclopedia of Geography, McGowan (2010) suggests "[ $t$ ]he most common topic has dealt with the recruitment of players for sports teams at both the collegiate and the professional levels". This includes spatial issues around talent development and identification (ID). Despite this, in a talent ID report prepared for the AFL in 2007 by one of the sport's most experienced recruiters (Turnbull 2007) the only specific reference made to socio-spatial issues is a brief sub-section on "family influences and social support".

Until recently, most research into talent identification has been uni-dimensional (Abbott et al. 2002) but the multi-dimensional factors associated with talent production are now starting to be considered (see Nieuwenhuis, Spamer and Rossum 2002; Reilly et al. 2000). Yet even in the growing multi-dimensionality of sports talent production, there is a dearth of spatial and social data that addresses causal factors in the identification and development of sporting talent (Abernethy and Farrow 2005; Baker and Horton 2004). The talent ID developmental literature is dominated by a focus on birthdates, by which the maturity of children affects age-classification in junior sports competition, producing the so-called 'relative age' effect favouring those born in the early months of any given year (Nolan \& Howell 2010). However, recent research has confirmed spatial factors appear to matter more, with an association between place of birth and sports talent recruitment that is over and above that for birthdate effects (MacDonald et al. 2009). Interest has grown in the type of settlements that are producing sports talent. A series of studies has suggested towns and regions with populations of less than 500,000 persons were over-represented in Canadian National Hockey League players (Curtis and Birch 1987) US National Football League players (Côté et al. 2006; MacDonald et al. 2009) and Australian national athletes (Abernethy and Farrow 2005). Such birthplace effects may be due to differential opportunities offered in larger and smaller cities and their impacts on the development of expertise and skill (MacDonald et al. 2009:85). 
A major limitation of these pioneering studies on birthplace effects is that they are based on methods using unverified records (website data) that do not distinguish between an athlete's birthplace versus the actual location where junior skill development and competition took place. In countries such as Australia with high residential mobility, where close to 2 million people moved regions between 2001 and 2006 alone (Australian Bureau of Statistics 2009), exploring birthplace effects may be misleading. Further, the previous research does not tease apart the many possible spatial factors involved in training and skill development, although studies using retrospective interview methods with sports talent have been undertaken (see Côté, Ericsson and Law 2005). There are significant problems facing researchers attempting to identify and then, where possible, map spatial variation in sports talent development. These include difficulties in sourcing reliable data, problems of definition and measurement, and a lack of available methods. However, recent advances in geographic information systems (GIS) and the growing professionalism of elite sports management does open up the potential for new approaches and methods to be tried.

\section{The Structure of AFL and Pathways to Recruitment}

AFL is today one of the most profitable, most professional and best organised sports in Australia, attracting the highest attendances and television ratings of any sport in the country (Mitchell, Stavros and Stewart 2011). AFL headquarters, in the city of Melbourne, helps administer one of the largest formal mass participation junior sports activities in Australia, through its AusKick program (Hickey and Fitzclarence 2004). Junior participation is strong, especially in the traditional AFL states of Victoria, South Australia, Western Australia and Tasmania, but with a growing presence in Queensland and New South Wales. The pathway to playing in the professional AFL at national level generally commences with playing junior football for a local club or school, a stage now most commonly preceded by registration in the Auskick program, conducted through junior clubs and schools for primary-school aged children. The level of commitment and training becomes more significant from age 12 when competition points and full body contact is permitted. The AFL oversees junior competitions via state-based administrations for age groups 8 years and above and records registration information on players involved according to specific $A F L$ regions. These regions are discrete areas that may include a portion of a major metropolitan centre, or a significant number of towns and districts in a rural area. Talented players are often then recruited to what may be termed 'feeder' clubs such as those in the Victoria/NSW/Tasmania TAC Cup under-18s competition, and similar junior competitions in Perth and Adelaide, or to key schools and junior academies (such as Assumption College, north of Melbourne, or the Clontarf indigenous academy in Western Australia). Others toil away against older players in local leagues, especially in rural and remote locations.

From there, the players may be recruited directly by one of the 18 AFL clubs in either of the 'national' or 'pre-season' drafts held each year, or they may enter those clubs by being listed as a 'rookie' and being upgraded later onto the club's senior list. Almost all current AFL players have been acquired by their teams via a draft or through a trade with another team that involves players that have been previously drafted. There are also more exotic means of entry, including for international players such as those recruited from Ireland, but the numbers of players whose key junior development region was outside Australia are very small $(<10)$ that these are not of great interest for broader talent identification. The AFL's drafting system began in 1986 with the intention of creating parity among the participant teams, with poorly performing teams receiving earlier draft selections than teams that have been more successful. Happell (2008) confirms that $89 \%$ of all players drafted between 1996 and 2004 went on to play at least one AFL game, suggesting that the AFL draft is a strong pathway to participation. 


\section{Approach and Method}

How would one ideally try to map the geography of junior talent production for a particular sport? Conceptually, we argue that one must begin with the spatial locations of talent at the time in the lifecourse where most skill development and expertise is first developed, and where early school or club competition occurs. This we defined as late primary school to early high school years (approximately ages 11 to 15) when junior talent generally begins to first be identified and selected for state or regional representative teams. Further we argue that talent production must be considered not primarily as a function of population (i.e. talent produced per young person resident in the area) but more as a function of participation (talent produced per young person registered and playing in the area).

Player background data, access to AFL talent development officials and a small amount of resourcing was made available to the authors and key collaborators in 2009 to trial a new approach. The resourcing allowed the first test to evaluate if this approach and method could deliver improved results for socio-spatial talent ID analysis. The Talent Tracker method uses geo-coded information about a talented athlete's place of junior production, synthesised with key participation data for that activity, and population data for children and young people of that age, to create a richer understanding of the geography of talent production. Our approach was to create a measure of talent development for regions, based on available datasets, including the annual AFL census, provided by the AFL and described below. Resource constraints prevented exhaustive retrospective interviews with players of the kind developed by Côté et al. (2005).

The principle performance measure is a region's 'talent yield' based on participation. Talent is defined as the number of AFL players who were either drafted through the main national draft or played at least one game of senior AFL football in the period 1997-2010 who developed in a specific region. While it was tempting to consider measures such as senior games played or best-and-fairest votes across player's careers, these are influenced by a much broader set of factors including team performance, (senior) club development and coaching, injury and even the position played by the player on the field. The measure of talent had to be focused instead on the earlier phase of recruitment to AFL lists. The place of junior development was measured by the place (club or school) where players were registered as playing AFL from the age of late primary/early high school (11 to 15 years of age). Only one place of development was identified for each player. For those players who moved during their 11-15 ages, priority was given to the club or school where they spent most time during the period, with further priority given to the late primary years in cases where approximately equal time was spent in two regions. Participation is defined as the number of 13-18 year old males registered for either club and/or school football in each AFL region. Initially we sought to use Auskick data as a measure of junior participation, being the AFL's primary junior participation program. However, Auskick participation entailed anything from involvement in a short school program through to significant commitment to a long season of weekly matches and activities. Registered players in the 13-18 year old competitions provided a much more robust dataset. The National Census of Australian Football (NCAF) is compiled with the peak AFL organisations in each state. This resource has been undertaken by Street \& Ryan annually since 2002. Spatially, this census uses 94 identified AFL regions; including 38 metropolitan and 56 country regions. Peak AFL organisations are responsible for recording the number of registered players within their jurisdiction for each Australian Football program area, including:

○ Auskick (the entry level program for children)

○ club football (encompassing junior, youth and open classifications) 
○ school football (encompassing primary and secondary schools)

○ formal recreational football programs

Importantly, the NCAF only includes formal registered participants in organised competitions and programs. It excludes informal/recreational football matches and competitions arranged by organisations other than football clubs, associations, or schools (Street \& Ryan 2009:18). The NCAF's rigour is enhanced by its being conducted by the same organisation that conducts a similar census for Cricket Australia. The level of detail and attention given to both school and club participation figures is considerable. The NCAF includes procedures to eliminate 'double counting' of players, including that Auskick participants must identify whether they also participate in school and/or community football competitions And it excludes those who participate only in promotional football programs such as clinics, school visits, knock-out competitions and other promotional games, due to the short duration of their involvement (Street \& Ryan 2009:19). The AFL talent 'yield' is therefore defined as the ratio of talent to participation in each of the 94 regions, expressed as talent produced vs. average participation per year.

Data on player place of junior development was sourced initially by provision from AFL of national draft records, which from the year 2005 had comprehensively documented the key junior club or school location for players, as defined above. This accounted for approximately half of the overall sample of 1,290 AFL players, allocating them to a particular club or school. Further investigations for the set of players with missing records involved player-by-player tracking, with information provided by informants including state-based AFL historians, state-based talent identification managers, and junior and feeder club officials. Published secondary data sources were thoroughly scoured, particularly using popular internet search engines for articles on player's backgrounds. Players were not approached directly to provide personal information to reduce ethical concerns. Preliminary lists of talent identifying place of junior development were twice distributed to state-based AFL officials for clarification and revision. Key problems with data collection included pinpointing the precise location of a player's place of junior development, especially for players who moved residential location during their late primary/early high school years. Another problem was the sheer workload required to achieve complete records for such a large sample. Lowprofile players who may have played only one or two AFL games occasionally required hours of investigation to determine their correct junior development location. When compiled and cross-checked, each player's place of junior development data was geocoded using ArcGIS software and the results aggregated to the level of AFL regions provided as shapefiles by the AFL. Participation data from the AFL census for the years 2002 to 2009 for 13-18 year old males was compiled and then geo-coded for each of the 94 regions, from which an annual average participation figure was derived to facilitate a more meaningful ratio of talent yield. The AFL regions were snapped to the nearest census collector district (CCD) boundaries, albeit most already used existing boundaries for statistical local areas (SLAs) which are aggregations of CCDs. The end product was a set of maps and coded tables for each region showing junior talent production and junior participation in AFL football, as defined earlier. The tables were transferred to MS Excel for basic analysis, including calculation of the ratio of talent yield (talent to participation).

It is acknowledged there are some significant limitations with these methods. Firstly, though every effort was made to create a consistent and accurate database of AFL players by place of junior development for the study period, the various sources used introduce some potential for erroneous allocation of players to particular regions. This 
was particularly the case where some players had moved from their primary development region to another in early high school and where their high school enrolment was the only residential data able to be accessed. Secondly, there are several players who did not start playing Australian football until after the age of 15 . This is particularly problematic due to AFL recruiters giving increased attention to targeting talented athletes from other sports in recent years. But even so we remain confident of the basic rationale for determining key developmental locations at the 11-15 year old period. Thirdly, there were a few cases where decisions on whether the high school or junior club was the more influential developmental location could not be determined and hence the junior club was chosen in preference to a high school given the likelihood that the player had commenced playing at that club in his primary school years.

\section{Results}

The Talent Tracker results for AFL for the period 1997-2010 are provided in Table 1. The results are mapped for all of Australia in Figure 1 to display the spatial variation in junior talent production. Some caution must be used in reading these results. In particular, a very small change in talent produced (even just one senior AFL player) in a region with low participation levels, such as Mackay, would see it rise or fall in the table dramatically. That said, the results show high talent production in the traditional AFL states of Western Australia, South Australia, Victoria and Tasmania, with much less being produced in New South Wales and Queensland. But regional variations at a more local level are significant. For instance, the 'Southern Central (Hobart)', 'Southern Eastern' and 'Southern North' regions of Tasmania, and Darwin in the Northern Territory all sit in the top six regions for talent produced across the nation. However, adjacent regions in Tasmania ('Northern' and 'Southern South') and the Northern Territory (Katherine) produced no talent over the same time period.

Table 1. Talent Yield and Junior Male Player Participation, AFL regions, 19972010.

\begin{tabular}{|l|l|l|l|l|l|}
\hline State & AFL REGION & $\begin{array}{l}\text { Talent } \\
\text { produced } \\
\text { from } \\
\mathbf{1 9 9 7 - 2 0 1 0} \\
\text { (Players } \\
\text { drafted and/or } \\
\text { played one or } \\
\text { more senior } \\
\text { AFL games) }\end{array}$ & $\begin{array}{l}\text { Average } \\
\text { talent } \\
\text { produced } \\
\text { per year } \\
\text { (Talent/14) }\end{array}$ & $\begin{array}{l}\text { Average } \\
\text { annual } \\
\text { junior } \\
\text { participant } \\
\text { S } \\
\text { (Registered } \\
\text { male players } \\
\text { aged 13-18) }\end{array}$ & $\begin{array}{l}\text { Talent } \\
\text { Yield } \\
\text { (Talent } \\
\text { Produced per } \\
\text { 1000 } \\
\text { Participants) }\end{array}$ \\
\hline TAS & $\begin{array}{l}\text { Southern Central } \\
\text { (Hobart) }\end{array}$ & 10 & 0.71 & 314 & 31.85 \\
\hline SA & Eagles & 19 & 1.36 & 678 & 28.02 \\
\hline TAS & Southern East & 11 & 0.79 & 466 & 23.61 \\
\hline NT & Darwin & 26 & 1.86 & 1229 & 21.16 \\
\hline TAS & Southern North & 12 & 0.86 & 575 & 20.87 \\
\hline SA & Glenelg & 21 & 1.50 & 1071 & 19.61 \\
\hline WA & Mid West & 15 & 1.07 & 801 & 18.73 \\
\hline SA & West Adelaide & 17 & 1.21 & 918 & 18.52 \\
\hline WA & East Fremantle & 28 & 2.00 & 1519 & 18.43 \\
\hline WA & Wheatbelt & 13 & 0.93 & 707 & 18.39 \\
\hline VIC & Calder & 70 & 5.00 & 4262 & 16.42 \\
\hline SA & Central Districts & 11 & 0.79 & 672 & 16.37 \\
\hline
\end{tabular}




\begin{tabular}{|c|c|c|c|c|c|}
\hline VIC & Sandringham & 75 & 5.36 & 4727 & 15.87 \\
\hline SA & Sturt & 13 & 0.93 & 828 & 15.70 \\
\hline NSW & Albury Murray & 20 & 1.43 & 1280 & 15.63 \\
\hline WA & Subiaco & 17 & 1.21 & 1097 & 15.50 \\
\hline VIC & Hampden & 27 & 1.93 & 1823 & 14.81 \\
\hline WA & Great Southern & 12 & 0.86 & 843 & 14.23 \\
\hline WA & Perth & 26 & 1.86 & 1839 & 14.14 \\
\hline WA & Claremont & 23 & 1.64 & 1638 & 14.04 \\
\hline $\mathrm{SA}$ & Yorke & 16 & 1.14 & 1140 & 14.04 \\
\hline SA & Port Adelaide & 8 & 0.57 & 573 & 13.96 \\
\hline VIC & Geelong & 43 & 3.07 & 3170 & 13.56 \\
\hline WA & Swan Districts & 21 & 1.50 & 1657 & 12.67 \\
\hline $\mathrm{SA}$ & Lincoln & 15 & 1.07 & 1227 & 12.22 \\
\hline VIC & $\begin{array}{l}\text { Nth Central- } \\
\text { Central Murray }\end{array}$ & 19 & 1.36 & 1578 & 12.04 \\
\hline VIC & Oakleigh & 56 & 4.00 & 4657 & 12.02 \\
\hline VIC & Eastern & 62 & 4.43 & 5218 & 11.88 \\
\hline VIC & Northern (VIC) & 40 & 2.86 & 3371 & 11.87 \\
\hline VIC & NorthEast Border & 33 & 2.36 & 2799 & 11.79 \\
\hline WA & South Fremantle & 17 & 1.21 & 1454 & 11.69 \\
\hline TAS & NW Burnie & 11 & 0.79 & 941 & 11.69 \\
\hline SA & Norwood & 17 & 1.21 & 1460 & 11.64 \\
\hline VIC & East Gippsland & 27 & 1.93 & 2322 & 11.63 \\
\hline $\mathrm{SA}$ & North Adelaide & 8 & 0.57 & 708 & 11.30 \\
\hline WA & Midlands & 10 & 0.71 & 893 & 11.20 \\
\hline NT & Alice Springs & 7 & 0.50 & 703 & 9.96 \\
\hline SA & Northern (SA) & 10 & 0.71 & 1008 & 9.92 \\
\hline VIC & Wimmera & 12 & 0.86 & 1238 & 9.69 \\
\hline VIC & Goulburn/Murray & 31 & 2.21 & 3208 & 9.66 \\
\hline VIC & Bendigo & 21 & 1.50 & 2175 & 9.66 \\
\hline VIC & Western Country & 10 & 0.71 & 1109 & 9.02 \\
\hline VIC & Ballarat & 22 & 1.57 & 2454 & 8.96 \\
\hline VIC & Dandenong & 47 & 3.36 & 5380 & 8.74 \\
\hline QLD & Gold Coast & 24 & 1.71 & 2758 & 8.70 \\
\hline SA & Barossa & 5 & 0.36 & 581 & 8.61 \\
\hline $\mathrm{SA}$ & Murray Mallee & 10 & 0.71 & 1173 & 8.53 \\
\hline SA & South Adelaide & 7 & 0.50 & 822 & 8.52 \\
\hline VIC & LaTrobe Valley & 25 & 1.79 & 3050 & 8.20 \\
\hline TAS & NW Devonport & 4 & 0.29 & 511 & 7.83 \\
\hline VIC & Sunraysia Mallee & 9 & 0.64 & 1268 & 7.10 \\
\hline NSW & Riverina & 8 & 0.57 & 1205 & 6.64 \\
\hline QLD & Capricornia & 3 & 0.21 & 456 & 6.58 \\
\hline WA & Kimberley & 4 & 0.29 & 618 & 6.47 \\
\hline WA & South west & 15 & 1.07 & 2351 & 6.38 \\
\hline VIC & Western Metro & 22 & 1.57 & 3463 & 6.35 \\
\hline $\mathrm{SA}$ & South east (SA) & 11 & 0.79 & 1741 & 6.32 \\
\hline TAS & Launceston & 7 & 0.50 & 1190 & 5.88 \\
\hline
\end{tabular}




\begin{tabular}{|c|c|c|c|c|c|}
\hline WA & West Perth & 10 & 0.71 & 1756 & 5.69 \\
\hline $\mathrm{SA}$ & Adelaide Hills & 2 & 0.14 & 363 & 5.51 \\
\hline NSW & Sydney Northside & 10 & 0.71 & 1821 & 5.49 \\
\hline WA & Goldfields & 5 & 0.36 & 945 & 5.29 \\
\hline QLD & Sunshine Coast & 7 & 0.50 & 1357 & 5.16 \\
\hline QLD & Brisbane SE & 11 & 0.79 & 2319 & 4.74 \\
\hline WA & East Perth & 6 & 0.43 & 1333 & 4.50 \\
\hline QLD & Brisbane North & 9 & 0.64 & 2001 & 4.50 \\
\hline QLD & Cairns & 4 & 0.29 & 908 & 4.41 \\
\hline NSW & Sydney South & 3 & 0.21 & 719 & 4.17 \\
\hline WA & Peel & 8 & 0.57 & 1953 & 4.10 \\
\hline NSW & MIA Broken Hill & 5 & 0.36 & 1433 & 3.49 \\
\hline QLD & Brisbane West & 6 & 0.43 & 1829 & 3.28 \\
\hline ACT & ACT & 4 & 0.29 & 1238 & 3.23 \\
\hline QLD & Mackay & 1 & 0.07 & 341 & 2.93 \\
\hline NSW & $\begin{array}{l}\text { Greater Western } \\
\text { Sydney }\end{array}$ & 2 & 0.14 & 732 & 2.73 \\
\hline QLD & Darling Downs & 2 & 0.14 & 763 & 2.62 \\
\hline SA & Coorong & 3 & 0.21 & 1279 & 2.35 \\
\hline QLD & Wide Bay & 1 & 0.07 & 515 & 1.94 \\
\hline NT & Arnhem & 1 & 0.07 & 541 & 1.85 \\
\hline WA & Pilbara & 1 & 0.07 & 595 & 1.68 \\
\hline QLD & Townsville & 1 & 0.07 & 602 & 1.66 \\
\hline $\mathrm{SA}$ & Fleurieu & 1 & 0.07 & 676 & 1.48 \\
\hline NSW & South Coast & 1 & 0.07 & 688 & 1.45 \\
\hline NSW & Hunter Central & 2 & 0.14 & 1783 & 1.12 \\
\hline NSW & Sydney South west & 1 & 0.07 & 1350 & 0.74 \\
\hline NT & Barkly & 0 & 0.00 & 181 & 0.00 \\
\hline QLD & Cape York & 0 & 0.00 & $-*$ & 0.00 \\
\hline NSW & Central West & 0 & 0.00 & 338 & 0.00 \\
\hline NSW & Illawarra & 0 & 0.00 & 500 & 0.00 \\
\hline NSW & Inner Sydney & 0 & 0.00 & 974 & 0.00 \\
\hline NT & Katherine & 0 & 0.00 & 410 & 0.00 \\
\hline NSW & Northern (NSW) & 0 & 0.00 & 703 & 0.00 \\
\hline TAS & Northern (TAS) & 0 & 0.00 & 776 & 0.00 \\
\hline TAS & Southern South & 0 & 0.00 & 458 & 0.00 \\
\hline QLD & Western Qld & 0 & 0.00 & 28 & 0.00 \\
\hline \multicolumn{2}{|c|}{ Average per region } & 13.7 & 0.98 & 1431.5 & 8.84 \\
\hline \multicolumn{2}{|c|}{ TOTAL } & 1290 & & & \\
\hline
\end{tabular}

* NB No participation data for Cape York has been collected in AFL censuses to date. 
Figure 1. Talent Yield (Talent Produced per 1000 Participants) for AFL Regions in Australia, 1997-2010.

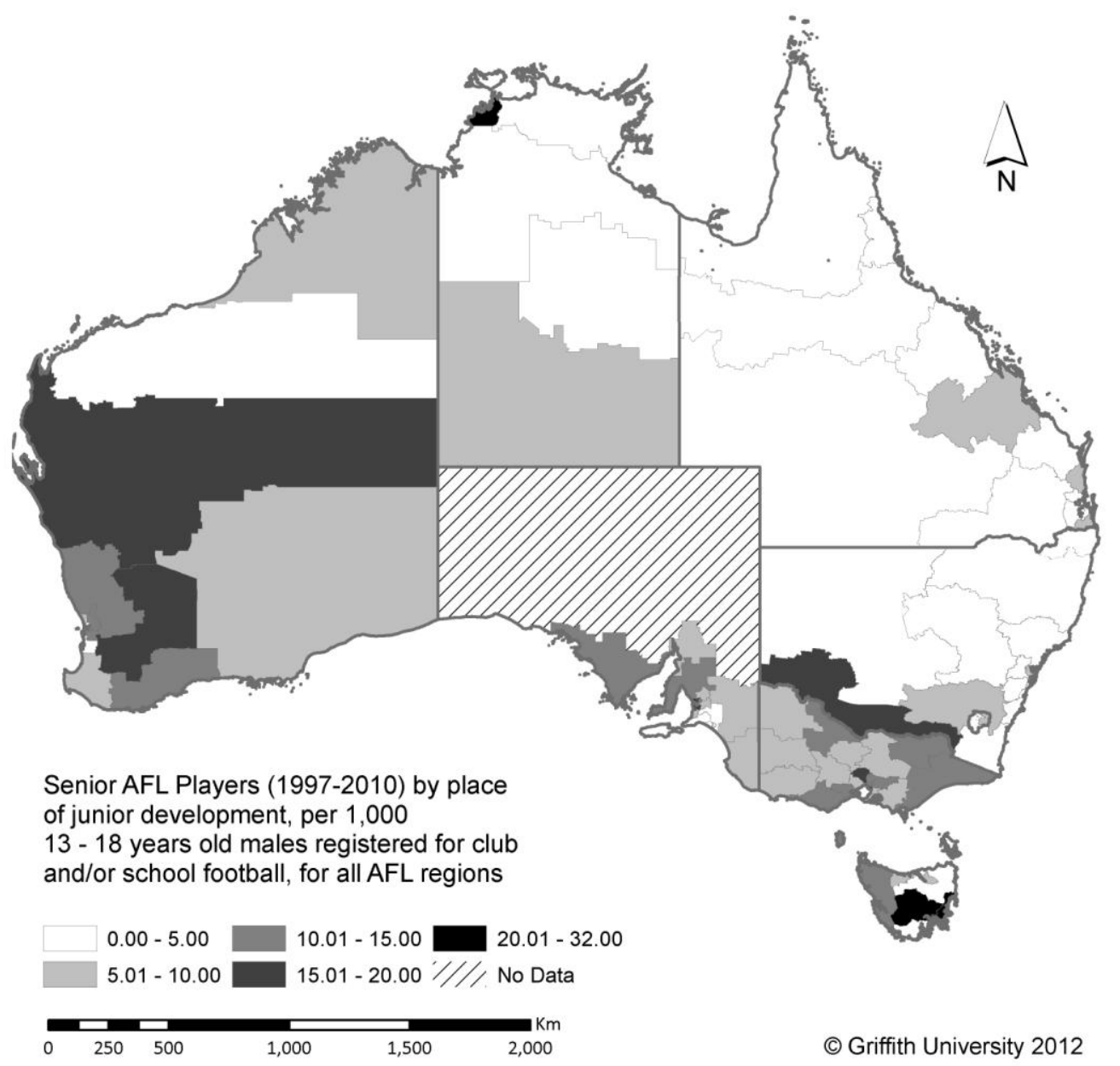

Clear spatial patterns emerge at the national scale. The first is in regards the low talent yields of regions in New South Wales (NSW) and Queensland, the two non-traditional AFL states, which are immediately apparent in Figure 1. Excepting the Riverina and Albury Murray regions and the two metropolitan regions of Sydney Northside and Sydney South, there are very few AFL players produced in NSW. As with all of Western and Northern Queensland, most of regional NSW has a much stronger affiliation to rugby league, with few AFL clubs and competitions. But though there are boys playing AFL in many of these parts of Queensland and NSW, per junior participant, very few are coming through to be recruited and play senior professional AFL. Not one Queensland AFL region has a talent yield statistic above the national average of 8.84 though the Gold Coast is close at 8.70.

Secondly, and subject to a few exceptions, the regions that are most over-achieving in talent production are outside the large metropolitan regions of Australia, and outside the heartlands of AFL football in Perth, Adelaide and Melbourne. Hobart, Darwin, and the Mid West and Wheatbelt regions of Western Australia are all regional. Yet the performance of such regional cities and towns in producing talent is often in dispute, including by authorities within the game. For instance, the role of Tasmania in producing AFL draftees was recently criticised by the AFL's longest serving coach and elder statesman, Kevin Sheedy. He suggested the state's capacity to produce AFL 
footballers was in steep decline and decried that 'There may be 15 Tasmanians on [AFL club] lists', insisting they should be doing better if they wish to obtain a licence for a permanent AFL club (Shaw 2012; Stubbs 2012). Our results suggest that Hobart appears to produce more talent per junior participant than anywhere else in Australia, and the adjacent 'Southern Eastern' and 'Southern North' regions are also some of the strongest talent producing regions for AFL. While the talent yields for other parts of the state are more modest, the 'hotspot' in southern Tasmania is clearly outperforming the rest of the nation, a result at odds with Sheedy's critique.

It is also important to look at the results at metropolitan scales, which are revealing of key spatial patterning. Figures 2, 3 and 4 provide more detailed mapping for Melbourne, Adelaide and Perth, respectively. These are the three largest cities in the traditional AFL states of Victoria, South Australia and Western Australia. 
Figure 2. Talent Yield (Talent Produced per 1000 Participants) for AFL Regions in Greater Melbourne, 1997-2010.
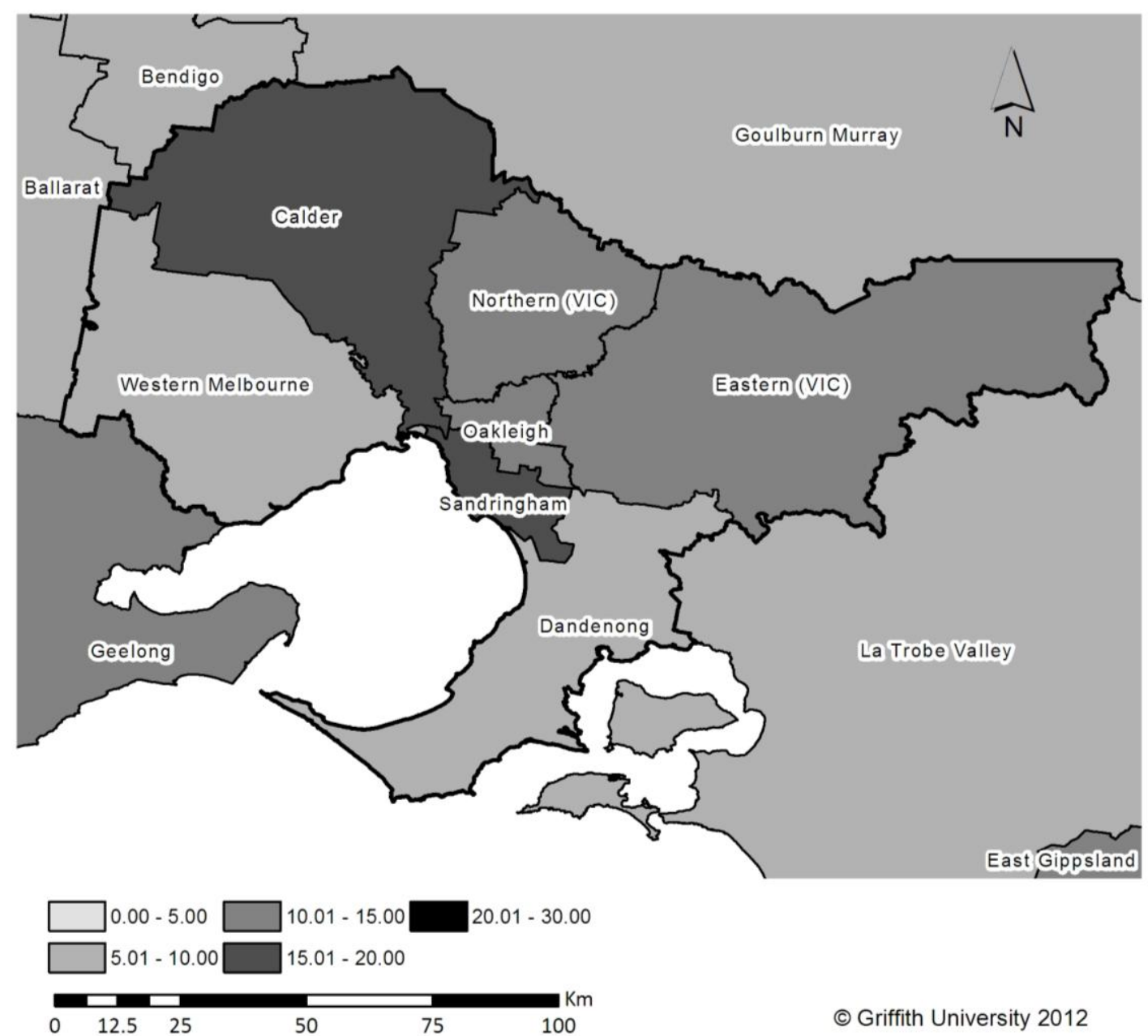
Figure 3. Talent Yield (Talent Produced per 1000 Participants) for AFL Regions in Greater Adelaide, 1997-2010.
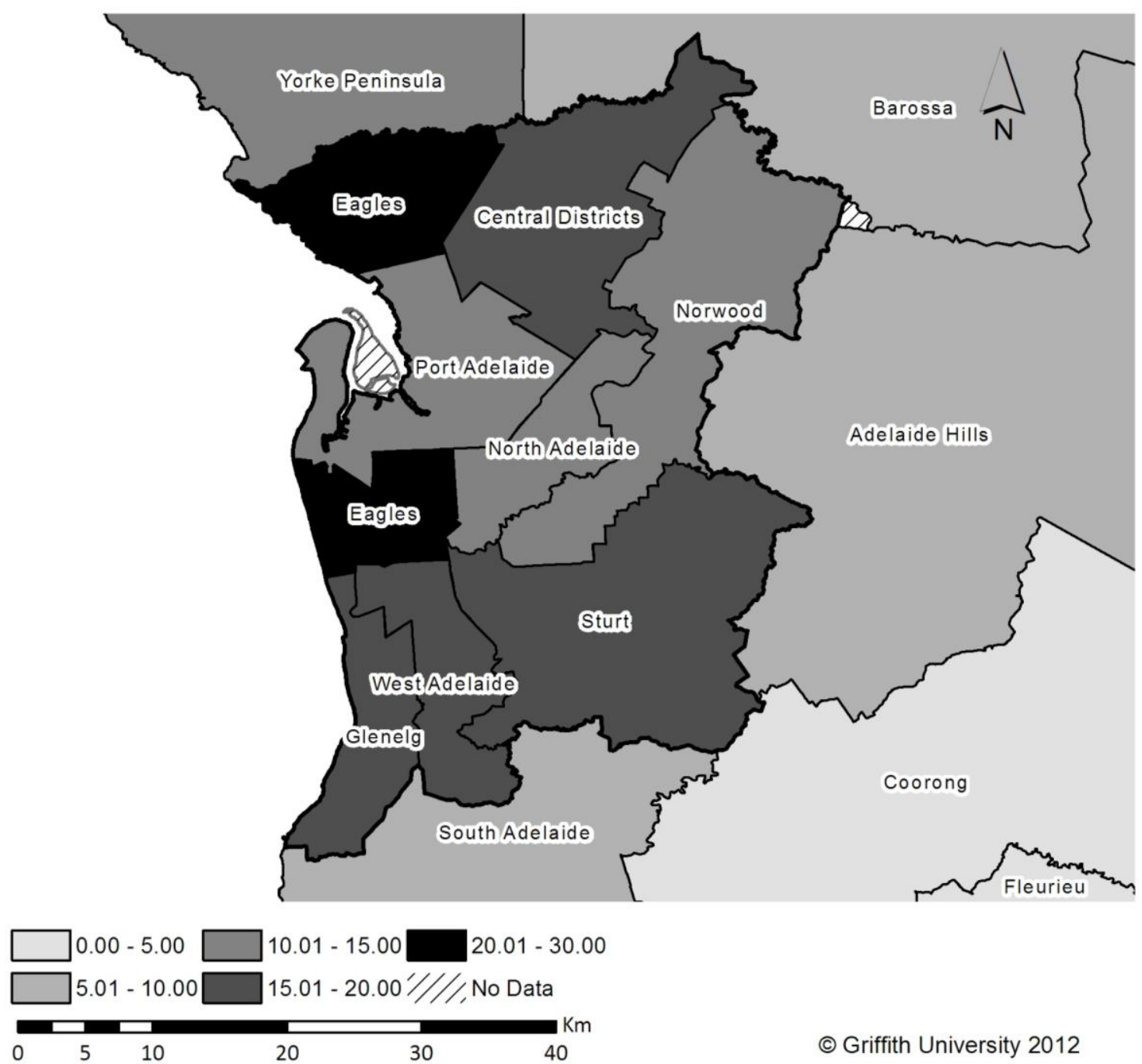

(c) Griffith University 2012 
Figure 4. Talent Yield (Talent Produced per 1000 Participants) for AFL Regions in Greater Perth, 1997-2010.

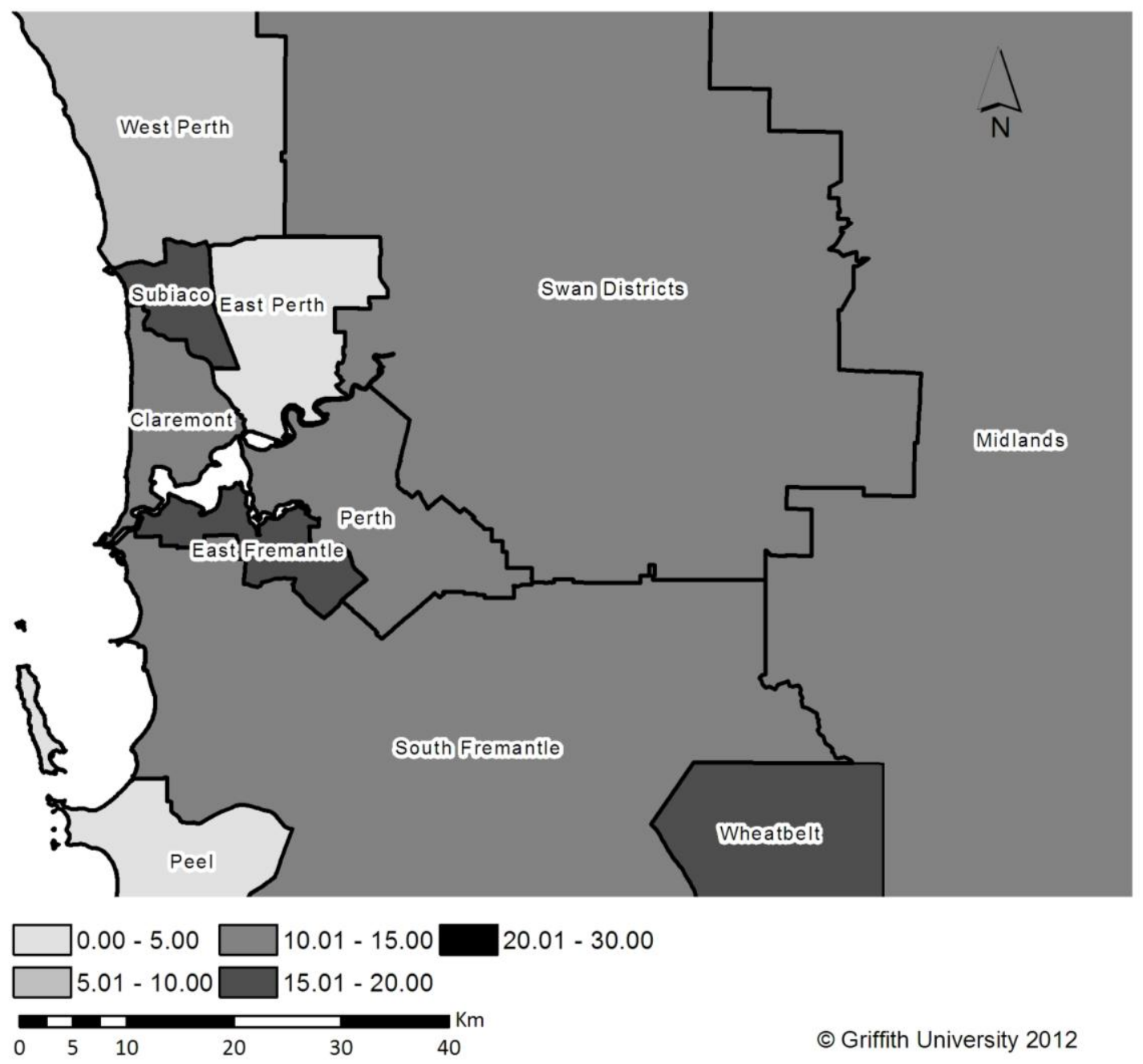

No consistent pattern emerges across the three main AFL cities. In Adelaide, an observable inner- vs. outer-suburban pattern is revealed, though the differences are not pronounced. The Central Districts region covering the working class areas to the north of the central business district around Elizabeth and Salisbury have relatively high talent yields, as do the Eagles (Woodville West-Torrens), Glenelg and southern outer-suburban regions. By contrast, the areas covering the centre of Adelaide and its west have more modest talent yields. In Melbourne and Perth the way the set of AFL regions are arranged does not really allow for clear inner- vs. outer-suburban patterns to emerge, albeit there is some suggestion that these effects may be apparent in Perth. There, the only under-performing region is East Perth, which includes the central business district, whereas Subiaco and the working class area of East Fremantle have produced very strong talent yields. In Melbourne, many AFL regions radiate long distances from the central-business district. Strongly performing regions are Calder, a mainly working class corridor north of the city centre, and Sandringham, along a more prosperous corridor to the south. The traditional working class areas of Western Melbourne and Dandenong (the latter which covers the Mornington Peninsular) produce only modest talent yields.

\section{Conclusion}

The Talent Tracker approach and methods provide means to more accurately identify the junior talent yield produced by specific regions. It provides a major advance on 
research methods that focused on birthplace as a proxy for place-of-production (i.e. Abernethy and Farrow 2005; Côté et al. 2006). The specification of an earlier developmental period and location also goes beyond the common practice of focusing on 'feeder' competitions or schools, which recruit from vast geographies and are often erroneously identified as the place of junior development. The method produces tables that allow comparison and ranking of regions and the visual display of spatial variation in performance at national and metropolitan scales.

One of the most significant contributions of this work is in the measure of talent yield based on talent produced as a share of junior participation, which proved relatively easy to operationalise for AFL football in Australia. It is not yet fully known if and how this can readily be operationalised for other sports in other locations (the authors and their collaborators are currently applying the approach to cricket and tennis in Australia) but it appears this may be possible in ways that will allow for some means of cross-sport comparison. There are numerous limitations to the methods which may prove problematic with other sports. Those sports with low numbers of elite talent, such as tennis, will require slightly different approaches. Sports such as AFL that capture data on previous junior club or school for elite talent appear to lend themselves most to the Talent Tracker methods. Where data is not readily available, researchers will need to resort to either the methods used here for AFL players drafted before 2005, or conduct direct surveys or interviews of players and sports talent to identify their junior place of development. This data could also be obtained by adding to existing elite player survey instruments overseen by sporting administrations, who are increasingly channelling talented athletes into academies in early adolescence.

The findings suggest that, even on a per-junior participant basis, the non-traditional AFL regions of NSW and Queensland are under-producing professional AFL recruits. At one level, one might expect this outcome as coaching and competition standards are likely to be inferior in regions with low levels of participation and without a strong AFL culture in schools and communities. Areas like the Gold Coast, central Sydney and some traditionally AFL-strong parts of Brisbane, with better talent yields, demonstrate it is possible for non-traditional AFL regions to produce AFL talent, but the factors determining these outcomes are not clear. The recent strategic turn to investing considerable financial resources in AFL academies in Queensland and NSW says something about the AFL's implicit recognition of slow progress in these states, with the launch of these new academies proclaiming that the model will "revamp" the AFL's talented player pathway in the northern states. Each of the four AFL clubs in these states are partnering with the AFL to identify, attract and develop players as young as 12 years of age, taking their development through to drafting age for the National Draft and Rookie Draft ${ }^{1}$. The factors behind the inner- vs. outer-suburban patterns observed in Adelaide and perhaps in Perth are also unknown. Tentative explanations might include differences in the availability of playing fields, demographic factors such as the proportion of young males in the population, and the availability of competing leisure activities across inner and outer areas. That many working-class areas are overproducing talent in Adelaide, Perth and Melbourne, albeit with exceptions, suggests socio-demographic factors may be influential.

The results for AFL open up numerous avenues for further research. There is the potential to use Getis $\mathrm{Ord}^{2}$ statistics to further identify and explore key clusters of AFL

\footnotetext{
${ }^{1}$ http://www.aflq.com.au/index.php?id=86

${ }^{2}$ Given a set of weighted data points, the Getis-Ord Gi statistic identifies those clusters (hot spots) of points with values higher in magnitude than you might expect to find by random chance.
} 
regions that appear to be 'hot-spots' of talent over-production. There is the potential not only to explore such issues as town size effects (whether players come from cities and towns of more than 500,000 people) but also to explore other socio-demographic factors that may be associated with higher or lower sports talent production. The authors are presently matching these spatial datasets with other measures to explore issues such as how transport accessibility and remoteness, and how socio-economic status, affects talent production, with this work in progress. Further, the successful trial of Talent Tracker with the AFL opens the capacity to explore talent production in other sports, and indeed other cultural (music, dance) and scholastic (literacy, numeracy) pursuits.

The paper highlights the power of empirical sports geography to inform debates about differences in sports landscapes, such as in the case of Tasmania and its performance in producing AFL players, which was subject to unreasonable conjecture. The research also demonstrates clearly the value of the geographical lens, which has generally been underused by sports administrators in Australia, and which is often applied superficially within broader historical, sociological and cultural studies of sport. As sporting agencies begin to produce spatial datasets of the quality of the AFL census there will be greater potential for geographers to contribute to key research questions about sport in the years to come.

\section{Acknowledgements}

This work was initially funded by a small grant provided by the AFL and Griffith University, and later an Australian Research Council - Linkage Project (LP 221008) exploring a much broader range of factors, which is supported by the Australian Sports Commission, the AFL, Cricket Australia and Tennis Australia. Talent Tracker would not have been possible without the support of the AFL and a number of key officers and informants, and we are particularly indebted to the many AFL historians, AFL officials and others who helped complete the database of players by place of junior production. Significant assistance was provided by Street Ryan and Associates, who were generous in sharing key data. Sincere thanks are given to our colleagues Dwight Zakus, Murray Bird, Kristine Toohey and other investigators on the ARC grant underpinning the work. Special thanks to Emily Hatfield who provided tireless assistance in gathering the data and preparing much of the early GIS analysis and Lavinia Poruschi who completed it. Thanks also to Rick Evans, Maryam Shobeirinejad and Joshua Skinner for their GIS support. The views expressed are solely those of the authors and do not represent the views of any institution. The authors take full responsibility for all errors and omissions.

\section{References}

Abbott, A., D. Collins, R. Martindale, and K. Sowerby. 2002. Talent identification and development: an academic review - a report for SportScotland by the University of Edinburgh. Edinburgh, UK: SportScotland.

Abernethy, A.B. and D. Farrow. 2005. "Contextual factors influencing the development of expertise in Australian athletes." Presented at Promoting Health and Performance for Life; Proceedings of the ISSP 11th World Congress of Sport Psychology, 15-19 August, 2005, Sydney.

Australian Bureau of Statistics. 2009. "Relocation Across the Nation: internal migration and population growth." in Australian Social Trends. Canberra: ABS.

Bailey, R., D. Collins, P. Ford, Á. MacNamara, M. Toms, and G. Pearce. 2010.

"Participant Development in Sport: An Academic Review." Leeds, UK: sports coach UK and Sport Northern Ireland.

Baker, J. and S. Horton. 2004. "A review of primary and secondary influences on sport expertise." High Ability Studies 15(2):211-228. 
Bale, J. 2003. Sports geography. London ; New York: Routledge.

Burke, M. and G. Woolcock. 2009. "Getting to the game: travel to sports stadia in the era of transit-oriented development." Sport in Society: Cultures, Commerce, Media,

Politics 12(7):890-909.

Collins, M. 2003. "Sport and Social Exclusion." Routledge.

http://Griffith.eblib.com.au/patron/FullRecord.aspx?p=180634

Côté, J., K.A. Ericsson, and M.P. Law. 2005. "Tracing the Development of Athletes

Using Retrospective Interview Methods: A Proposed Interview and Validation

Procedure for Reported Information." Journal of Applied Sport Psychology 17(1):1-19.

Côté, J., D.J. Macdonald, J. Baker, and B. Abernethy. 2006. "When 'where' is more

important than 'when': Birthplace and birthdate effects on the achievement of sporting

expertise." Journal of Sports Sciences 24(10):1065-1073.

Curtis, J. and J. Birch. 1987. "Size of Community of Origin and Recruitment to

Professional and Olympic Hockey in North America." Sociology of Sport Journal 4(3):229-244.

Happell, C. 2008. 11\% of those picked will never play a game. Retrieved March 5, 2012, from http://www.crikey.com.au/Media-Arts-and-Sports/20081127-AFL-draft.html

Harris, J. and N. Wise. 2011. "Geographies of Scale in International Rugby Union." Geographical Research 49(4): 375-383

Hickey, C. and L. Fitzclarence. 2004. "'I like football when it doesn't hurt": factors influencing participation in Auskick." ACHPER Healthy Lifestyles Journal 51(4):7-11. MacDonald, D.J., M. Cheung, J. Côté, and B. Abernethy. 2009. "Place but not Date of Birth Influences the Development and Emergence of Athletic Talent in American Football." Journal of Applied Sport Psychology 21(1):80-90.

Maguire, J. 1995. "Common ground? Links between sports history, sports geography, and the sociology of sport." Sporting traditions: the journal of the Australian Society for Sports History 12(1):3-25.

McGowin, D. 2010. "Sports, Geography of." in Encyclopedia of Geography, edited by B. Warf. Thousand Oaks, USA: SAGE Publications.

Mitchell, H., C. Stavros, and M.F. Stewart. 2011. "Does the Australian Football League Draft Undervalue Indigenous Australian Footballers?" Journal of Sports Economics 12(1):36-54.

Nicholson, M. and R. Hoye. 2008. "Sport and Social Capital." Taylor \& Francis. http://Griffith.eblib.com.au/patron/FullRecord.aspx?p=338919

Nieuwenhuis, C.F., E.J. Spamer, and J.H.A.van Rossum. 2002. "Prediction Function for Identifying Talent in 14- to 15-Year-old Female Field Hockey Players." High Ability Studies 13(1):21-33.

Nolan, J. and G. Howell. 2010. "Hockey Success and Birth Date: The Relative Age Effect Revisited.” International Review for the Sociology of Sport 45(4): 507-512. Reilly, T., A.M. Williams, A. Nevill, and A. Franks. 2000. "A Multidisciplinary Approach to Talent Identification in Soccer." Journal of Sports Sciences 18(9):695-702. Rimmer, P.J. and R.J. Johnston. 1967. "Areas of community interest in Victoria as indicated by competitive sport." Australian Geographer 10(4):311-313.

Rosso, E. 2010. "From informal recreation to a geography of achievement: women's soccer in South Australia." Geographical Research 48: 181-196.

Rowe, D. and P. McGuirk. 1999. "Drunk for Three Weeks: sporting success and city image." International Review for the Sociology of Sport 34(2):125-141.

Shaw, R. 2012. "Sheedy says Tassie must earn right to have own team." The Examiner [online] 6 April 2012. Available online at

http://www.examiner.com.au/news/local/sport/football-australian-rules/sheedy-saystassie-must-earn-right-to-have-own-team/2477932.aspx? src=rss. 
Street \& Ryan. 2009. "Australian Football Census 2009: reporting on the health of our national game - National Census of Australian Football Participation and Players." Melbourne: Street \& Ryan.

Stubbs, B. 2012. "Sheedy's Rocket for Tassie Footy." The Mercury [online], 5 April 2012. Available online at http://www.themercury.com.au/article/2012/04/05/315931_afl.html.

Tonts, M. and K. Atherley. 2005. "Rural Restructuring and the Changing Geography of Competitive Sport." Australian Geographer 36(2):125-144.

Turnbull, J. 2007. Analysis of the research and literature into the methods of successfully identifying and developing Talent in Sport from a global perspective: Report to the AFL, provided to research team August 2008.

Zakus, D., J. Skinner, and A. Edwards. 2009. "Social capital in Australian sport." Sport in Society 12(7):986-998. 